\title{
Epidemiology of the rotator cuff tears: a new incidence related to thyroid disease
}

\author{
Francesco Oliva ${ }^{1}$ \\ Leonardo Osti ${ }^{2}$ \\ Johnny Padulo 3,4 \\ Nicola Maffulli5,6
}

1 Department of Orthopaedic and Traumatology, University of Rome "Tor Vergata", School of Medicine, Rome, Italy

2 Unit of Arthroscopic and Sports Medicine, Hesperia Hospital, Modena, Italy

3 University eCampus, Novedrate, Italy

4 National Centre of Medicine and Science in Sports (CNMSS), Tunis, Tunisia

5 Centre for Sports and Exercise Medicine Queen Mary University of London Barts and The London School of Medicine and Dentistry, Mile End Hospital London, UK

6 Head of Department of Physical and Rehabilitation Medicine, University of Salerno, Italy

\section{Corresponding author:}

Francesco Oliva

Department of Orthopaedic and Traumatology,

University of Rome "Tor Vergata"

School of Medicine, Rome

V. le Oxford 81

00133 Rome, Italy

E-mail: olivafrancesco@hotmail.com

\section{Summary}

Background: in the last years the incidence of rotator cuff tears increased and one main cause still waiting to be clarified. Receptors for thyroid hormones in rotator cuff tendons suggest possible effects on tendons metabolism and status. We undertook a retrospective, observational cohort study of $\mathbf{4 4 1}$ patients who underwent arthroscopic and mini-open repair for non traumatic degenerative rotator cuff tears.

Methods: all the patients, predominantly females $(63 \%)$, were interview to assess the relationship (frequency for class age "20 yrs" and factor analysis) between lesions of the rotator cuff with the following variables: gender, thyroid disease, smoker, taking medications for diabetes, hypertension or high cholesterol; presence of associated conditions (diabetes, hypertension, hypercholesterolemia).
Results: thyroid disease is highly frequently (until $63 \%$ for $60<80 \mathrm{yrs}$ ) in females group independent to the age. Conversely, males showed a high frequency for smoker $37<62 \%$ until 80 yrs and $50 \%$ hypercholesterolemia over $\mathbf{8 0}$ yrs for the clinical variable studied.

Conclusions: this is the first clinical report that shown a relationship between thyroid pathologies and non-traumatic rotator cuff tear as increased risk factors.

KEY WORDS: age-group, clinical field, epidemiology, gender, healthcare, musculoskeletal disorders, rotator cuff tears, tendons, thyroid hormones, upper extremity.

\section{Introduction}

Rotator cuff tear pathogenesis is still unknown. It is likely to involve a number of factors such as a genetic predisposition, extrinsic impingement and biomechanical imbalance from structures surrounding the cuff and intrinsic degeneration from changes within the tendon itself and finally co-morbidities ${ }^{1-4}$. Rotator cuff tears are the most common non-traumatic upper limb cause of disability in people over 50 years, and they may be considered as a natural age-related process, with a statistically significant increase after that chronological age. In the United Kingdom, the prevalence of shoulder problems based on consultations in primary care is estimated to be $2.4 \% 5$. Between 30 and $70 \%$ of such shoulder pain arises from disorders of the rotator cuff 6,7 . United States during 2002 there were 4.5 million physician visits and approximately 40,000 inpatient procedures for problems of the rotator cuff, with a mean cost of $14,000 \$$ per case $^{8}$. The incidence of cuff tears ranges from $5^{7}$ to $40 \%$, although it is difficult to ascertain the true incidence because the rotator cuff tears are not always symptomatic. Approximately one third of silent rotator cuff tears will become symptomatic trough the years ${ }^{9}$. Imaging can reveal cuff tears in approximately $40 \%$ of persons over the age of 50 years and this rate rises to $54 \%$ in those $>60$ years and $65 \%$ in persons over age 70 years $^{10}$. However, there is a strong variability in prevalence rates and epidemiological features of rotator cuff tears among studies, gender and co-morbidities may play a significant role on the burden of shoulder disease ${ }^{11}$.

Particularly, women reported a greater functional 
deficit than men for common shoulder diagnoses ${ }^{12}$ Indeed, women had a statistically significant and negative relationship with shoulder scoring scale, and this correlation becomes stronger in aged ones ${ }^{7}$. Shoulder pain increased in female patients aged 70 to 79 years, and in white women had the highest prevalence of neck pain (15\%) while in black women, shoulder pain is predominant $(24 \%)^{8}$. A recent epidemiological study based on The Health Improvement Network (THIN) database reported ${ }^{13}$ that this condition is more common in women than in men (90 cases per 100,000 people-years in women, and 83 per 100,000 people-years in men; $p<0.001$ ). It is not clear if "gender" can influence also the clinical outcome after treatment. Females may experience poor outcomes in terms of rehabilitation because of a more complex pattern of impairment caused by rotator cuff tears on pain in daily living ${ }^{3}$. On the other hand, Mc Kee et al. ${ }^{14}$ demonstrated that biological factors such as "age and gender" are not significantly related to outcome. The prevalence of rotator cuff tears in women can be partly explained that gender and hormonal variation (estrogens and thyroxin) ${ }^{15}$ influences the biology tendinous, affecting both collagen and matrix metabolism at a structural and biochemical level ${ }^{16}$. For these reasons, endocrine disorders lead to an early development of shoulder symptoms, a longer natural history, and a greater need of surgical treatment. Among co-morbidities, an high presence of: hormone-related gynecologic diseases, autoimmune pathologies, hypothyroidism, rheumatoid arthritis and type 1 diabetes mellitus were found; most frequently in women affected by calcifying tendinopathy ${ }^{17}, 18$. Medical co-morbidities negatively influence pain and functionality in patients with a chronic rotator cuff tear. While the most frequently detected ones are low back pain, hypertension and arthritis ${ }^{19}$. Indeed, medical co-morbidities have a strong impact on the general health status of patients, also after successful rotator cuff surgical repair. In a study on 408 patients, a relationship between hypertension and rotator cuff tears was detected with a 2 times increased risk and a tendency to develop a large tear 20.

Conversely, smoke is one risk factor present in rotator cuff tears, besides the smoke its vasoconstrictor action leads to a decrease in delivering oxygen in critical zones (especially supraspinatus and infraspinatus tendon-bone insertion zone $)^{21}$ and contributes to failed tendon healing ${ }^{13}$. However, a recent case control study found no evidence of negative impact of a previous smoking history ${ }^{22}$. Patients with rotator cuff tears had a higher incidence of hypercholesterolemia and cholesterol byproducts may alter the biomechanical tendon properties ${ }^{23}$. Elevated serum lipid profile, such as in metabolic syndrome, are related to tendon ruptures ${ }^{14}$, and diabetes mellitus has a negative influence on tendon healing, because of its metabolism altered pathways and the higher rate of complications and infection after rotator cuff surgical repair ${ }^{15}$.

Published studies have showed small sample size, single-centre and/or retrospective ${ }^{24}$. Despite our limited understanding of the pathogenesis and natural history of tears of the rotator cuff, we continue treating this disorder as best we can because of the large numbers of patients involved $25-27$. Therefore the aim of the present study was to clarify the association between rotator cuff tears with common metabolic diseases and life style.

\section{Patients and methods}

The inclusion criteria to interview (June, $2013 \mathrm{yr}$ ) for the strength of the study was the complete tear of the rotator cuff in female and male Italian patients. All the patients were part of the data base registry of two authors/researchers (L.O. and F.O) and had undergone arthroscopic confirmation of the rotator cuff tear and subsequent repair in mini-open "48\%" (F.O.) or arthroscopic fashion "52\%" (L.O.). Metallic anchors and single knots were delivered to the cuff tear were used in both the surgical procedures. The exclusion criteria were: rheumatic pathologies, traumatic rupture of the rotator cuff. After evaluating the inclusion and exclusion criteria, 441 patients operated between 2010 and 2012 yrs were selected as study subjects. There were 161 males (37\%) age 24-86 yrs, height 156-192 cm, weight 50-155 kg, BMI 17.72-45.29 $\mathrm{kg} \cdot \mathrm{m}^{-2}$, and 280 females (63\%) with age 22-90 $\mathrm{yrs}$, height $147-181 \mathrm{~cm}$, weight $47-110 \mathrm{~kg}$, BMI 17.51$43.51 \mathrm{~kg} \cdot \mathrm{m}^{-2}$ (Tab. 1).

All experimental procedures were approved by the University Human Research Ethics Committee according to MLTJ guideline ${ }^{29}$. The audio-consent (digitally recorded) was obtained from the participants after being thoroughly informed of the study design in the first interview. All the interviews were undertaken in the same period ( 1 to 30 June) by one researcher. After anthropometric data, the clinical variable included were: gender, thyroid disease, smoker; taking medications (diabetes, hypertension, hypercholesterolemia) to verify and guarantee the consistence of the information's; associated diseases (diabetes, hypertension, hypercholesterolemia).

\section{Statistical analysis}

The variable examine of the Italian population was analysed fully and for different age gender. The value was showed as mean $\pm S D$. Student $t$-test was used to revealed anthropometric differences between females and males. The factor analysis was carried out using 9.0 SPSS software. Factors were extracted using the Maximum Likelihood Solution and orthogonally rotated using Varimax with Kaiser normalisation. Cattell's screen test ${ }^{28}$ was used to determine the number of factors to be extracted. Examination of the screen plot indicated that no more than two factors should be extracted. Factors were extracted from the rotated factor matrix by selecting variables with a factor load- 
Table 1. Anthropometric data of the patients.

\begin{tabular}{|c|c|c|c|c|c|}
\hline Sex & Age Group (y) & Age (yrs) & Height $(\mathrm{cm})$ & Weight $(\mathrm{kg})$ & $\mathrm{BMI}\left(\mathrm{kg} \cdot \mathrm{m}^{-2}\right)$ \\
\hline \multirow{4}{*}{$\begin{array}{l}\frac{0}{\widetilde{\sigma}} \\
\stackrel{\Xi}{0} \\
\stackrel{L}{L}\end{array}$} & $20-40$ & $31.60 \pm 6.70$ & $167 \pm 6.94$ & $66 \pm 15$ & $24 \pm 5.72$ \\
\hline & $40-60$ & $53.60 \pm 5.04$ & $163 \pm 6.22$ & $69 \pm 10$ & $26 \pm 4.14$ \\
\hline & $60-80$ & $69.27 \pm 5.63$ & $161 \pm 5.58$ & $69 \pm 13$ & $26 \pm 4.63$ \\
\hline & $80-90$ & $83.91 \pm 3.30$ & $161 \pm 3.99$ & $65 \pm 6$ & $25 \pm 3.40$ \\
\hline \multirow{4}{*}{$\frac{\frac{0}{\pi}}{\sum}$} & $20-40$ & $33.04 \pm 4.64$ & $178 \pm 5.95$ & $76 \pm 7$ & $24 \pm 1.75$ \\
\hline & $40-60$ & $52.84 \pm 5.29$ & $175 \pm 5.69$ & $81 \pm 12$ & $27 \pm 3.12$ \\
\hline & $60-80$ & $68.81 \pm 5.12$ & $172 \pm 7.04$ & $82 \pm 14$ & $28 \pm 3.63$ \\
\hline & $80-90$ & $83.00 \pm 2.00$ & $171 \pm 3.30$ & $76 \pm 6$ & $26 \pm 2.29$ \\
\hline
\end{tabular}

Anthropometric (means and standard deviation) data for "Male and Female" respect to age groups, respectively.

ing of $\geq 0.4$ for inclusion within that factor. As a result, a few variables were common to more than one factor. Pearson's product moment correlation coefficient (r) was used to examine correlations between clinical variables. The magnitude of the correlations was determined using the modified scale by Hopkins et al. ${ }^{30}$ : $r<0.1$ trivial; 0.1-0.3 small; 0.3-0.5 moderate; 0.5-0.7 large; 0.7-0.9 very large; $>0.9$ nearly perfect and 1 perfect. The level of significant was set at $p<0.05$. To assess the incidence for each clinical variable ${ }^{29}$ in male and female, respectively, frequency analysis was performed.

\section{Results}

The data analysis for anthropometric measures showed significant differences $(p<0.001)$ between males $(58 \pm 14.43 \mathrm{yrs})$ and females $(63 \pm 11.64 \mathrm{yrs})$ for age (Fig. $1)$, body height $(174 \pm 6.66 / 162 \pm 5.30 \mathrm{~cm})$ and body weight $(68 \pm 11.89 / 81 \pm 12.23 \mathrm{~kg})$ respectively. No differences $(p=0.08)$ were found between males and females regarding the two surgical procedures performed. Frequency analysis showed different trends on clinical variables related to the gender (Tab. 2). Thyroid disease is highly frequency $27<63 \%$ in females, independent of age, particularly the large sample size 157 with age $60<80$ yrs showed $63 \%$ the frequency on thyroid disease. In male group the high frequency was for Smoker $37<62 \%$ until 80 yrs for the clinical variable studied, while only 2 subjects with age up $80 \mathrm{yrs}$ showed the presence of the hypercholesterolemia.

When comparing smoker and no smoker in two different gender (Tab. 3) the frequency analysis showed counter balanced phenomenon; indeed the high frequencies of thyroid disease was $73 \%$ in Female (Smoker) and $24 \%$ in Male (Not Smoker). While, Factor analysis showed four principal component with $21 / 15 / 14 / 13 \%$ of the Variance for female group (Tab. 4) related to: diabetes, hypertension and hypercholesterolemia; the $4^{\text {th }}$ factor was related to thyroid disease. There was a strong correlation $(r<0.90, p<$ 0.001 ) between taking medications (diabetes, hyper-

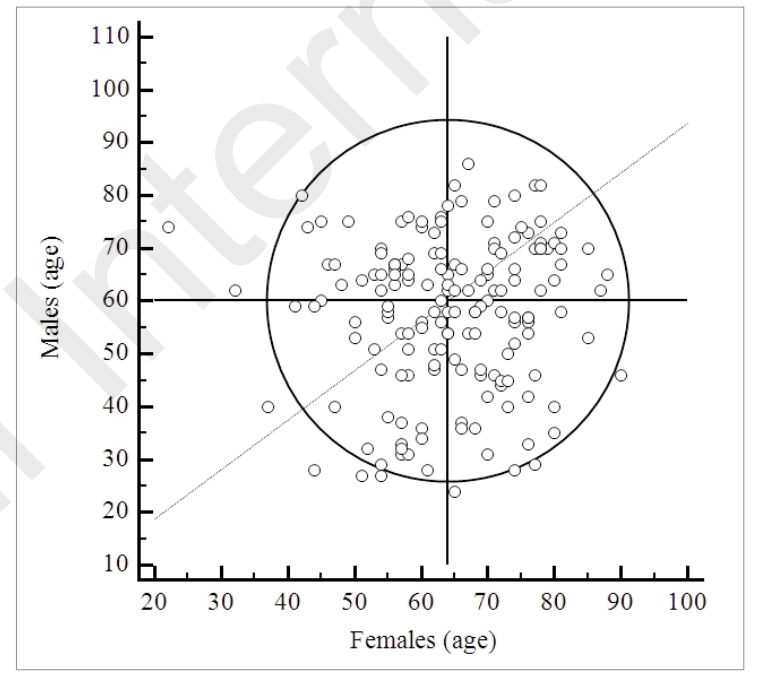

Figure 1. Sample size "Male and Female".

tension, hypercholesterolemia) and associated diseases (diabetes, hypertension, hypercholesterolemia). Besides, there was evidence of a statistically significant association between thyroid disease and smoker ( $r=0.130$ "Small", $\mathrm{p}=0.039)$ in female group. The variance for male group (Tab. 4) was $11 / 15 / 16 / 29 \%$ related to: diabetes, hypertension and hypercholesterolemia; while the $4^{\text {rd }}$ factor was related to smoker. A negative statistically significant correlation $(r<-0.180, p=0.033$ ) was found between smoke and hypercholesterolemia.

\section{Discussion}

Despite rotator cuff tendon tears are one of the most investigated tendons diseases, meta-analysis, and guidelines are still lacking of final and evidenced conclusions $^{31}$. Clear the intrinsic factors behind the etiopathogenesis (in our case metabolic diseases especially, the thyroid disease association with rotator cuff tears) seems to appear as an interesting para- 


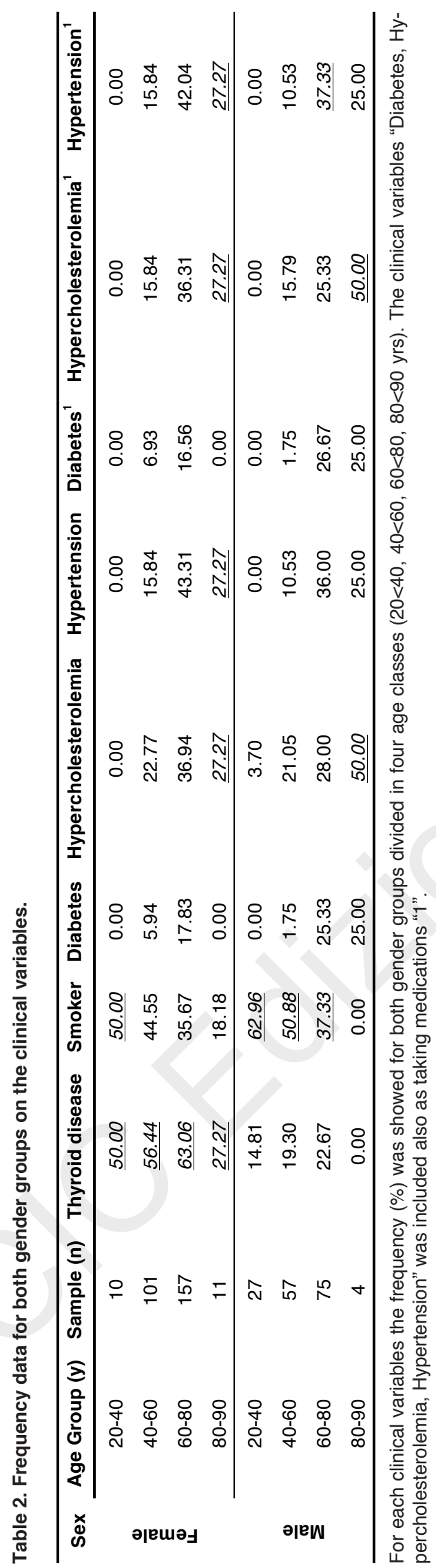

Table 3. Frequency data for both gender groups on thyroid disease.

\begin{tabular}{lll}
\hline Condition & Male & Female \\
\hline Smoker & 18 & 73 \\
\hline No Smoker & 24 & 58 \\
\hline
\end{tabular}

For thyroid disease the frequency (\%) was showed for both gender groups between smoker and not smoker.

digm. This is the first report which investigated and demonstrated a possible role of thyroid hormones on modifying and increasing the rate of non traumatic rotator cuff tear. The higher frequency $(63 \%)$ detected a clear scientific evidence based on higher sample power in female group, while in both groups the relevance of the clinical variables with taking medications was satisfied. The gender has been an increased risk factor enhanced by the higher incidence $(56 \%$ of the total female group between 60 and $80 \mathrm{yrs}$ ) of thyroid pathologies among the females. At the same time the small $(r=0.130-p=0.039)$ relationship showed between smoke and rotator cuff tear in female group represent the low incidence respect to male group.

This study involved a large series of patients with confirmed rotator cuff tears at arthroscopy excluding patients with trauma history, co-morbidities have been widely investigated according to the well documented risk factor reported in the recent literature ${ }^{32}$. The clinical gap between the onset of an anatomical RCT and the onset of the pain can be addressed not only by an overuses or the simply aging or genetically predisposing factors or traumas that are the main actors in the tendons tears but even in an metabolic substrate as the thyroid diseases which should influence the failed healing response in some subjects, causing the final symptomatic tears ${ }^{17}$. We previously show the presence that the TRa/b nuclear receptor isoforms are present in healthy and pathologic rotator cuff tendons. Furthermore THs enhance, in vitro, tenocyte growth, and counteract apoptosis in healthy tenocytes isolated from tendon in a dose- and timedependent manner ${ }^{3,27}$. This clinical observational study confirm the first basic science resources at least in women with a rotator cuff tears.

Limits of this study are: 1) retrospective study does not correlate the size of the rotator cuff lesion with co-morbidity factor risk; 2) does not analyse in the single patient the amount of co-morbidities involved but spread the analysis in the age group for each gender; 3) does not give information about the history (progression time from asymptomatic to symptomatic tear comparing the thyroid pathology affected group to the non affected); 4) does not specify the degree and type of thyroid pathology. Obesity, hypertension, hypercholesterolemia, smoking, diabetes play a role as a documented risk factor and thyroid disease itself can interact with risk factors such as obesity, hypertension and hypercholesterolemia related to this disease with both lower and hyperfuction.

After this epidemiological survey and the previous basic 
Table 4. Total variance explained by the first four factors for both gender group.

\begin{tabular}{|c|c|c|c|}
\hline Components (\%Variance) & & Clinical Variables & \\
\hline \multicolumn{4}{|l|}{ Male } \\
\hline 29.36 & Hypercholesterolemia $(0.715)$ & M. Cholesterol (0.702) & $\begin{array}{l}\text { Hypertension } \\
(0.637)\end{array}$ \\
\hline 16.43 & Weight (0.904) & Height (0.648) & \\
\hline 15.36 & M. Diabetes (0.703) & Diabetes (0.682) & \\
\hline 11.00 & Smoker (0.698) & & \\
\hline \multicolumn{4}{|l|}{ Female } \\
\hline 21.30 & M. Hypertension (0.699) & Hypertension (0.676) & Age $(0.568)$ \\
\hline 14.93 & $\begin{array}{l}\text { M. Hypercholesterolemia } \\
(-0.751)\end{array}$ & $\begin{array}{l}\text { Hypercholesterolemia } \\
(0.737)\end{array}$ & \\
\hline 14.57 & M. Diabetes $(0.770)$ & S & \\
\hline 13.30 & Thyroid (0.648) & & \\
\hline
\end{tabular}

For each clinical variables factor analysis was showed for both gender groups in four component analysis. The clinical variables "Diabetes, Hypercholesterolemia, Hypertension" was included also as taking medications "M".

science evidence published by our group ${ }^{3,27}$, we are strongly convinced that metabolic diseases can be enrolled as another important but not still clarified element in the etiopathogenesis of the rotator cuff tears. Maybe we cannot be concentrate only in a mechanical theories which do not addressed many of our questions around this matter. This attempt open a new significant association between rotator cuff tears and thyroid disease. Further clinical, epidemiological and basic science studies on others tendons tears or tendinopathies are needed to conclude that thyroid hormones are linked to the metabolism of tendons in adult age and can be a cofactors. We advocate more research in this field in the way to clarify even the outcome, the rehabilitation timing and the intrinsic tendon healing after a surgical repair are objectively altered by metabolic factors associated. Despite our limited understanding of the pathogenesis and natural history of tears of the rotator cuff we have been forced to continue treating this disorder as best we can because of the large numbers of patients involved. In the world of evidence-based medicine and scrutiny of surgical outcome, reliable answers to these questions are now overdue. These answers have, however, been elusive for some time mainly because of a multi-factorial pathology.

\section{Acknowledgements}

The authors gratefully thank all patients who took part in the study.

\section{Competing interest}

The authors declare non conflict of interest relate to the present article.

\section{Funding}

No funding was received for this investigation.

\section{Author contribution}

All authors contributed equally to this manuscript.

\section{References}

1. Del Buono A, Oliva F, Longo UG, et al. Metalloproteases and rotator cuff disease. J Shoulder Elbow Surg. 2012;21 (2):200-208.

2. Oliva F, Zocchi L, Codispoti A, et al. Transglutaminases expression in human supraspinatus tendon ruptures and in mouse tendons. Biochem Biophys Res Commun. 2009;379 (4):887-891.

3. Oliva F, Berardi AC, Misiti S, Falzacappa CV, lacone A, Maffulli $N$. Thyroid hormones enhance growth and counteract apoptosis in human tenocytes isolated from rotator cuff tendons. Cell Death Dis. 2013;4:e705.

4. Giai Via A, De Cupis M, Spoliti M, Oliva F. Clinical and biological aspects of rotator cuff tears. Muscles Ligaments Tendons J. 2013;3(2):70-79.

5. Linsell L, Dawson J, Zondervan K, et al. Prevalence and incidence of adults consulting for shoulder conditions in UK primary care; patterns of diagnosis and referral. Rheumatology (Oxford) 2006; 45(2):215-221.

6. Matsen FA, Titelman RM, Lippit SB, Wirth MA, Rockwood CA Rotator cuff. In The Shoulder, Third Edition, Rockwood Jr, C A, Matsen III, F A, (eds), Wirth, M A, Lippitt, S B, (assoc eds), W B Saunders Company, Philadelphia, PA. 2004;695-790.

7. Neer CS. Impingement lesions. Clin Orthop Relat Res. 1983;(173):70-77.

8. Oh LS, Wolf BR, Hall MP, Levy BA, Marx RG. Indications for rotator cuff repair: a systematic review. Clin Orthop Relat Res. 2007;55:52-63. 
9. Yamaguchi K, Tetro AM, Blam O, Evanoff BA, Teefey SA, Middleton WD. Natural history of asymptomatic rotator cuff tears: a longitudinal analysis of asymptomatic tears detected sonographically. J Shoulder Elbow Surg. 2001;10(3):199-203.

10. Sher JS, Uribe JW, Posada A, Murphy BJ, Zlatkin MB. Abnormal findings on magnetic resonance images of asymptomatic shoulders. J Bone Joint Surg Am. 1995;77(1):10-15.

11. Harryman DT, Hettrich CM, Smith KL, Campbell B, Sidles JA, Matsen FA III. A prospective multipractice investigation of patients with full-thickness rotator cuff tears: the importance of comorbidities, practice, and other covariables on self-assessed shoulder function and health status. J Bone Joint Surg Am. 2003;85-A(4):690-696.

12. Largacha $M$, Parsons IM, Campbell B, Titelman RM, Smith $\mathrm{KL}$, Matsen F III. Deficits in shoulder function and general health associated with sixteen common shoulder diagnoses: a study of 2674 patients. J Shoulder Elbow Surg. 2006;15(1):30-39.

13. White JJ, Titchener AG, Fakis A, Tambe AA, Hubbard RB, Clark DI. An epidemiological study of rotator cuff pathology using The Health Improvement Network database. Bone Joint J. 2014;96-B(3):350-353.

14. McKee MD, Yoo DJ. The effect of surgery for rotator cuff disease on general health status. Results of a prospective trial. J Bone Joint Surg Am. 2000; 82-A(7):970-979.

15. Hart DA, Archambault JM, Kydd A, Reno C, Frank CB, Herzog W. Gender and neurogenic variables in tendon biology and repetitive motion disorders. Clin Orthop Relat Res. 1998;(351):44-56

16. Oliva F, Berardi AC, Misiti S, Maffulli N. Thyroid hormones and tendon: current views and future perspectives. Concise review. Muscles Ligaments Tendons J. 2013;3(3):201-203.

17. Harvie P, Pollard TC, Carr AJ. Calcific tendinitis: natural history and association with endocrine disorders. J Shoulder Elbow Surg. 2007;16(2):169-173.

18. Oliva F, Giai Via A, Maffulli N. Physiopathology of intratendinous calcific deposition. BMC Med. 2012;10:95.

19. Tashjian RZ, Henn RF, Kang L, Green A. The effect of comorbidity on self-assessed function in patients with a chronic rotator cuff tear. J Bone Joint Surg Am. 2004;86-A(2):355362.

20. Gumina S, Arceri V, Carbone S, et al. The association be- tween arterial hypertension and rotator cuff tear: the influence on rotator cuff tear sizes. J Shoulder Elbow Surg. 2013;22(2):229-232.

21. Vogt MT, Simonsick EM, Harris TB, et al. Neck and shoulder pain in 70- to 79-year-old men and women: findings from the Health, Aging and Body Composition Study. Spine J. 2003;3(6):435-441.

22. Titchener AG, White JJ, Hinchliffe SR, Tambe AA, Hubbard $\mathrm{RB}$, Clark DI. Comorbidities in rotator cuff disease: a casecontrol study. J Shoulder Elbow Surg. 2014.

23. Jensen I, Nygren A, Gamberale F, Goldie I, Westerholm P. Coping with long-term musculoskeletal pain and its consequences: is gender a factor? Pain. 1994;57(2):167-172.

24. McElvany MD, McGoldrick E, Gee AO, Neradilek MB, Matsen FA III. Rotator Cuff Repair: Published Evidence on Factors Associated With Repair Integrity and Clinical Outcome. Am J Sports Med. 2014.

25. Harvie P, Ostlere SJ, Teh J, et al. Genetic influences in the aetiology of tears of the rotator cuff. Sibling risk of a full-thickness tear. J Bone Joint Surg Br. 2004;86(5):696-700.

26. Kannus $\mathrm{P}$, Jozsa L. Histopathological changes preceding spontaneous rupture of a tendon. A controlled study of 891 patients. J Bone Joint Surg Am. 1991;73(10):1507-1525.

27. Oliva F, Barisani D, Grasso A, Maffulli N. Gene expression analysis in calcific tendinopathy of the rotator cuff. Eur Cell Mater. 2011;21:548-557.

28. Preacher KJ, MacCallum RC. Exploratory factor analysis in behavior genetics research: factor recovery with small sample sizes. Behav Genet. 2002;32(2):153-161.

29. Padulo J, Oliva F, Frizziero A, Maffulli N. Muscles, Ligaments and Tendons Journal. Basic principles and recommendations in clinical and field science research. MLTJ. 2013;4:250-252.

30. Hopkins WG, Marshall SW, Batterham AM, Hanin J. Progressive statistics for studies in sports medicine and exercise science. Med Sci Sports Exerc. 2009;41(1):3-13.

31. Pedowitz RA, Yamaguchi K, Ahmad CS, et al. Optimizing the management of rotator cuff problems. J Am Acad Orthop Surg. 2011;19(6):368-379.

32. Tashjian RZ. Epidemiology, natural history, and indications for treatment of rotator cuff tears. Clin Sports Med. 2012;31 (4):589-604. 